\title{
Childhood trauma and cognitive functioning in individuals at clinical high risk (CHR) for psychosis
}

\author{
T. Velikonja ${ }^{1,2}$ (D), E. Velthorst ${ }^{1,2}$, J. Zinberg ${ }^{3}$, T. D. Cannon ${ }^{4}$, B. A. Cornblatt ${ }^{5}$, D. O. Perkins ${ }^{6}$, K. S. Cadenhead ${ }^{7}$, \\ M. T. Tsuang 7 , J. Addington ${ }^{8}$, S. W. Woods ${ }^{4}$, T. McGlashan ${ }^{4}$, D. H. Mathalon ${ }^{9}$, W. Stone ${ }^{10}$, M. Keshavan ${ }^{10}$, L. Seidman ${ }^{10}$ \\ and C. E. Bearden ${ }^{3}$ \\ ${ }^{1}$ Department of Psychiatry, Icahn School of Medicine, Mount Sinai, New York, NY, USA; ${ }^{2}$ Seaver Center of Research and Treatment, Icahn School of Medicine, Mount \\ Sinai, New York, NY, USA; ${ }^{3}$ Departments of Psychiatry and Biobehavioral Sciences and Psychology, Semel Institute for Neuroscience and Human Behavior, University \\ of California-Los Angeles, Los Angeles, CA, USA; ${ }^{4}$ Department of Psychiatry, Yale University, New Haven, CT, USA; ${ }^{5}$ Department of Psychiatry, Zucker Hillside \\ Hospital, Queens, NY, USA; ${ }^{6}$ Department of Psychiatry, University of North Carolina, Chapel Hill, NC, USA; ${ }^{7}$ Department of Psychiatry, University of California-San \\ Diego, La Jolla, CA, USA; ${ }^{8}$ Department of Psychiatry, Hotchkiss Brain Institute, University of Calgary, Calgary, Alberta, Canada; ${ }^{9}$ Department of Psychiatry, University \\ of California-San Francisco, San Francisco, CA, USA and ${ }^{10}$ Department of Psychiatry, Harvard Medical School at Beth Israel Deaconess Medical Center, Boston, MA, \\ USA
}

\begin{abstract}
Evidence suggests that early trauma may have a negative effect on cognitive functioning in individuals with psychosis, yet the relationship between childhood trauma and cognition among those at clinical high risk (CHR) for psychosis remains unexplored. Our sample consisted of $626 \mathrm{CHR}$ children and 279 healthy controls who were recruited as part of the North American Prodrome Longitudinal Study 2. Childhood trauma up to the age of 16 (psychological, physical, and sexual abuse, emotional neglect, and bullying) was assessed by using the Childhood Trauma and Abuse Scale. Multiple domains of cognition were measured at baseline and at the time of psychosis conversion, using standardized assessments. In the CHR group, there was a trend for better performance in individuals who reported a history of multiple types of childhood trauma compared with those with no/one type of trauma (Cohen $d=0.16$ ). A history of multiple trauma types was not associated with greater cognitive change in CHR converters over time. Our findings tentatively suggest there may be different mechanisms that lead to CHR states. Individuals who are at clinical high risk who have experienced multiple types of childhood trauma may have more typically developing premorbid cognitive functioning than those who reported minimal trauma do. Further research is needed to unravel the complexity of factors underlying the development of at-risk states.
\end{abstract}

Keywords: clinical high risk, childhood trauma, nonsocial cognition, psychosis, social cognition

(Received 14 April 2019; accepted 16 September 2019)

Childhood trauma stands as one of the most robust environmental risk factors for psychotic disorders (Bendall, Jackson, Hulbert, \& McGorry, 2008; Fisher et al., 2010; Matheson, Shepherd, Pinchbeck, Laurens, \& Carr, 2013; Trotta, Murray, \& Fisher, 2015; Varese et al., 2012) and has also been associated with attenuated (subthreshold) psychotic symptoms (Kraan et al., 2015; van Dam et al., 2012; Velikonja, Fisher, Mason, \& Johnson, 2015; Velthorst et al., 2013). Similar observations have been reported for young people at clinical high risk (CHR) for psychosis (Kraan et al., 2015), who have a substantially higher risk of developing a full-threshold psychosis than is observed in the general population (Fusar-Poli et al., 2012). Individuals who are at CHR are identified based on clinical criteria (also referred to as

Author for correspondence: Dr. Tjasa Velikonja, Department of Psychiatry, Icahn School of Medicine at Mount Sinai, 1 Gustave L Levy Pl., Psychiatry Box\# 1230, New York, NY 10029. E-mail: tjasa.velikonja@mssm.edu.

Cite this article: Velikonja $\mathrm{T}$ et al (2021). Childhood trauma and cognitive functioning in individuals at clinical high risk (CHR) for psychosis. Development and Psychopathology 33, 53-64. https://doi.org/10.1017/S095457941900155X psychosis risk syndrome) that include one of the following presentations: attenuated positive psychotic symptoms, genetic risk for schizophrenia and a significant decrease in functioning, or a brief, limited and intermittent full-blown psychotic symptom (Miller et al., 2002). A meta-analysis of childhood trauma (defined as the report of at least one traumatic experience such as emotional neglect and/or emotional, physical, or sexual abuse before the age of 17) in CHR studies reported a mean prevalence rate of $87 \%$ (Kraan et al., 2015), which is significantly higher than that seen in the general population (range 42.7-60.0\%; Addington et al., 2013; Tikka et al., 2013). Furthermore, clustering of victimization (co-occurrence of multiple forms of childhood abuse) is common (Dong et al., 2004; Kessler et al., 2010), and it is associated with even greater risk for developing psychotic symptoms (Arseneault et al., 2011; Kelleher, Keeley, et al., 2013).

One theory of the association between childhood trauma and psychotic symptomatology suggests that adverse childhood experiences may increase psychosis risk through their negative effects on social and nonsocial cognitive development (Rokita, Dauvermann, \& Donohoe, 2018). Because early childhood is a 
sensitive period for the development of attachment relationships (Dozier, 2008), exposure to traumatic events during this time may have irreversible effects on the mental processes that underlie socioemotional functioning. This hypothesis is supported by findings in the general population that indicate that individuals with a history of childhood trauma have poorer cognitive functioning than those without such history (Beers \& De Bellis, 2002; Koenen, Moffitt, Caspi, Taylor, \& Purcell, 2003; Mezzacappa, Kindlon, \& Earls, 2001; Navalta, Polcari, Webster, Boghossian, \& Teicher, 2006).

Cognitive deficits are well documented in individuals with established psychotic illness (Giuliano et al., 2012; Hou et al., 2016), and qualitatively similar (but less severe) deficits have been reported in CHR groups (Barbato et al., 2013; Bora \& Murray, 2014; Cannon et al., 2002; Fusar-Poli et al., 2012; Reichenberg et al., 2010; Thompson, Bartholomeusz, \& Yung, 2011) including impairments in social cognition (Piskulic et al., 2016), executive function (Fusar-Poli et al., 2012), processing speed (Kelleher, Clarke, Rawdon, Murphy, \& Cannon, 2013), and verbal- (Seidman et al., 2010) and working memory (Fusar-Poli et al., 2012). However, despite the growing evidence for an association between childhood trauma and cognitive functioning in various psychiatric disorders (Aas et al., 2011; Velikonja et al., 2019), findings in the psychosis literature are inconsistent (Campbell et al., 2013; Dauvermann \& Donohoe, 2019; Ucok et al., 2015). More specifically, a history of childhood trauma has been associated with both lower (Aas et al., 2011) and higher (Campbell et al., 2013) baseline cognitive functioning in individuals with psychotic illness relative to those without such history. Given such discrepancies in findings, many questions are still left unanswered. It remains unclear whether childhood trauma may have a different effect on social vs. nonsocial cognitive functions. Also, little attention has been given to the relationship between childhood trauma and specific cognitive domains among CHR youth. Notably, studies have shown that childhood trauma has a significantly greater effect on cognition among healthy individuals (Malarbi et al., 2017) than among individuals with psychotic illness (Vargas et al., 2019). Some have hypothesized that this might be because the effect of trauma is overpowered by factors that are associated with psychotic illness itself (e.g., genetic effects, medication use; van Os et al., 2017). Therefore, understanding the relationship between childhood trauma and cognition in subthreshold states might help to explain the inconsistencies in findings from clinical samples and would offer more insight into the pathogenesis of psychosis. In the only study to date exploring the association between childhood trauma and nonsocial cognition in CHR youth, Ucok et al. (2015) found an association between physical abuse (but not sexual/emotional abuse or emotional neglect) and cognitive deficits, in particular in the domains of attention, working memory, and cognitive flexibility. This study was limited by a relatively small sample and the absence of follow-up data, so the relationship of baseline cognition to psychotic conversion could not be explored, nor could the changes over time.

Importantly, childhood trauma may also have an effect on cognitive trajectories. In a study by Campbell et al. (2013), firstepisode psychosis patients with a history of childhood trauma had higher premorbid IQ (vs. those without childhood trauma) and showed significant cognitive decline after the onset of illness (as assessed by differences in premorbid IQ estimates relative to current IQ), whereas individuals without childhood trauma had a lower premorbid IQ but did not show a significant change after the onset of psychosis. This study's findings tentatively suggest different pathways to illness onset (i.e., those who develop psychosis with no history of childhood trauma may have early neurodevelopmental impairments that reveal vulnerability, whereas those who experience childhood trauma may be more typically developing, so they "require" an additional stressor to reach the psychosis threshold).

Considering the lack of previous research in this area (and noted discrepancies between findings in the above-mentioned studies), the current study was considered exploratory in nature, without any predefined hypotheses. Our primary purpose was to examine the association between multiple types of childhood trauma and baseline cognitive function scores in a large sample of individuals who were at CHR for psychosis. Moreover, while it was previously reported that childhood trauma does not contribute to the prediction of psychosis/conversion in our CHR sample (see Stowkowy et al., 2016), we do not yet know whether CHR converters with and without a history of (multiple types of) childhood trauma differ in their cognitive trajectories over the early course of illness. Our objective was to explore this in CHR converters by examining differences in cognitive changes from pre- to postconversion between those who reported multiple types of childhood trauma and those with no/one trauma.

\section{Method}

\section{Participants}

Clinical high risk (CHR) participants and healthy controls were recruited as part of the North American Prodrome Longitudinal Study 2 (NAPLS-2; Addington et al., 2012), which sought to evaluate the predictors and mechanisms of conversion to psychosis. All of the CHR participants met the criteria for prodromal syndromes (COPS; McGlashan, 2010), which is characterized by attenuated positive symptom syndrome (APSS), genetic risk and deterioration (GRD), and/or brief intermittent psychotic syndrome (BIPS). All of the participants that were included in our analysis completed a baseline clinical and cognitive assessment, and they were followed over a two-year period (at 6-, 12-, 18-, and 24-month follow-up assessments). For those who converted to psychosis, the follow-up assessment was completed at the time of psychotic conversion (Mean $=288.4$ days). The exclusion criteria for the CHR group included any current or lifetime Axis I psychotic disorders (identified by The Structured Clinical Interview for DSM-IV, SCID [First, 1995]), IQ of less than 70, history of a central nervous system disorder and/or substance dependence in the last six months. Use of antipsychotic medication was not an exclusion criterion if there was clear evidence that the antipsychotic was not prescribed for frank psychosis and if the CHR criteria continued to be met despite antipsychotic use. Control participants were considered eligible for the study if they did not meet any criteria for prodromal syndromes, had no current or past psychotic disorder or cluster A personality disorder diagnosis, were not using psychotropic medication, and did not have a family history (first-degree relatives) of any psychotic disorder. For more details about the study design and the inclusion and exclusion criteria see previous publications (Addington et al., 2012; Addington et al., 2015).

The study obtained ethical approvals by Institutional Review Boards at all eight sites (Addington et al., 2012) that were participating in NAPLS-2. An informed consent or assent (i.e., parental 
informed consent for minors) was obtained for all of the participants.

\section{Measures}

Prodromal syndromes, severity of symptoms, and psychotic conversion criteria

The Structured Interview for Prodromal-risk Syndromes (SIPS; Miller et al., 2003) was used to determine whether individuals met the criteria for prodromal syndromes. Also, for each $\mathrm{CHR}$ participant a vignette was developed for the purpose of obtaining a consensus diagnosis (once approved at the site level, it was discussed by members of each of the participating sites). The severity of symptoms was measured with the Scale of Psychosis-Risk Symptoms (SOPS; Miller et al., 2003), which contains four subscales: positive symptoms (hallucinations, delusions), negative symptoms (e.g., social anhedonia or withdrawal, decreased expression of emotions), disorganization (e.g., odd behavior or appearance), and general symptoms (e.g., sleep and motor disturbances).

Conversion to full-threshold psychosis was defined according to the presence of Psychosis Scale criteria on the SIPS (Miller et al., 2003), that is, any positive symptom of psychotic-level intensity (a score of 6) that is sustained for at least an hour per day at an average of four days per week during the past month or symptoms that have seriously affected functioning (e.g., participant severely disorganized or dangerous to self/others).

\section{Childhood trauma}

Childhood trauma up to the age of 16 was primarily assessed by using a semistructured interview (The Childhood Trauma and Abuse Scale; Janssen et al., 2004), which covers emotional neglect, physical abuse, psychological abuse, and sexual abuse. In addition, participants were asked if they had experienced either psychological or physical bullying.

Each of the individual childhood trauma types were rated as 0 $=$ Trauma absent or $1=$ Trauma present. A total trauma score was then created to include the sum of all five types of childhood trauma: physical, psychological, or sexual abuse, emotional neglect, and bullying (combined psychological and/or physical). In total, $77.2 \%(N=483)$ of $\mathrm{CHR}$ group reported experiences of at least one type of trauma. Because of this high prevalence of childhood victimization in this group and building on the literature outlining the effect of multivictimization on psychotic symptoms (Arseneault et al., 2011; Kelleher, Keeley, et al., 2013), a more restrictive trauma cutoff was adopted for our analysis. That is, childhood trauma was considered to be "Present" if two or more types of trauma were reported/identified (46.8\%, $N=293$ of CHR) and "Absent" if none or one type of trauma was reported/identified (53.2\%,N=333 of CHR individuals). Also, the more restrictive threshold allowed us to create roughly equivalent groups, and this subsequently gave us more power for additional analyses (comparing "multiple trauma types present/ absent" with "those who reported no/one trauma" for nonconverters and converters separately).

\section{Cognitive functioning}

The neurocognitive battery included measures of nonsocial and social cognition. Ten measures of nonsocial cognition that cover seven cognitive domains as identified by the MATRICS Consensus Cognitive Battery (Nuechterlein et al., 2008) were used. Processing speed was measured by: (a) The Trail Making
Test (TMT), Part A (Reitan Neuropsychology Laboratory, 1944), where the participant is asked to draw a line to connect consecutively numbered circles; (b); Category Fluency (Animal Naming; Spreen, 1998), which involved the listing of as many animals as possible in 60 seconds; and (c) the Symbol Coding subtest of the Brief Assessment of Cognition in Schizophrenia (Keefe et al., 2004), where the subject fills in the corresponding numbers beneath each mark. Verbal learning was assessed with the Hopkins Verbal Learning Test-Revised (HVLT-R; Benedict, Schretlen, Groninger, \& Brandt, 1998), in which the participant is asked to repeat a list of 12 words in three taxonomic categories over three trials. Working memory was measured by (a) The Spatial Span subtest of the Wechsler Memory Scale, Third Edition (WMS3; Wechsler, 1997), during which the participant's nonverbal working memory is assessed; and (b) The Letter Number Span (Gold, Carpenter, Randolph, Goldberg, \& Weinberger, 1997) task, where the participant is asked to mentally recall and rearrange in a numerical and alphabetical order strings of letters and numbers that are of varying lengths. For reasoning and problem solving, the Mazes subtest of the Neuropsychological Assessment Battery (NAB; Stern, 2003) was administered, using seven paper-and-pencil mazes of increasing difficulty. Visual learning was measured by using the Brief Visuospatial Memory Test-Revised (BVMT-R; Benedict, Schretlen, Groninger, Dobraski, Sphritz, 1996), in which the participant is asked to reproduce six geometric figures from memory. A computeradministered measure, the Continuous Performance Test-Identical Pairs (CPT-IP; Cornblat \& Erlenmeyer-Kimling, 1985), was used to assess the attention/vigilance domain.

In addition, three domains of social cognition were evaluated:

(1) Theory of mind was measured by the social inference subscale of The Awareness of Social Inference Test (TASIT; McDonald, Flanagan, Rollins, \& Kinch, 2003). The TASIT includes 16 short videos wherein actors are engaged in everyday conversations and use lies and sarcasm. Four questions (using Yes/No/Don't know response options) on each video relate to what characters are thinking, doing, feeling, and saying, respectively. The total score ranges from 0 to 64 . The measure has been widely used with patients who have been diagnosed with schizophrenia (Green et al., 2012; Kern et al., 2009; Sparks, McDonald, Lino, O’Donnell, \& Green, 2010) and individuals at CHR for psychosis (Green et al., 2012).

(2) Emotion perception (affect processing) was gauged by two computerized assessments: The Penn Emotion Recognition task (ER40; Gur et al., 2002) and the Penn Emotion Differentiation task (EDF40; Kohler, Bilker, Hagendoorn, Gur, \& Gur, 2000), both previously adopted in schizophrenia (Goghari \& Sponheim, 2013) and CHR (Kohler et al., 2014) studies. In ER40, the participant is shown a face and asked to indicate the emotion, choosing between anger, fear, neutral, happy, or sad. In EDF40, the participant is asked to identify the most intense emotion (either happiness or sadness) between the two faces shown. The total score on both measures ranges from 0 to 40 .

(3) Social perception was assessed by a shortened version of the Relationship Across Domains (RAD-45; Sergi et al., 2009) measure that was specifically developed for patients with schizophrenia (Sergi et al., 2009). The RAD is based on relational models theory (Fiske, 1991), which argues that people use their implicit knowledge of four relational models to 
regulate their social relationships and social interactions (Fiske, 1991). The first model, named Community Sharing, is focused on commonality among persons in the relationship (i.e., being equivalent and undifferentiated). The Authority Ranking model focuses on asymmetric hierarchical ordering that makes a distinction between "decisions makers" and "followers." The third model, Equality Matching, is based on reciprocity of like behaviors among members and one-to-one distribution of efforts and resources. In contrast, in the Market Pricing model, the relationships are organized by ratios and rates, where each member is entitled to a fair rate of return that is proportional to their contribution. In the RAD task, vignettes are presented, each involving a male-female dyad whose interpersonal behaviors reflect one of the four relational models (see Fiske, 1991). Each vignette is followed by three statements, and the participants are required to use the information from the vignette to indicate (with Yes/No response options) whether the behaviors described in each statement are likely to occur. Performance is measured by the total number of correct responses (ranging from 0 to 45 ).

\section{Statistical analysis}

Differences in demographic, clinical, and cognitive scores between the study groups (i.e., healthy controls (HC) vs. CHR, and CHR with multiple types of childhood trauma (CHR/Multiple Trauma Types +) vs. CHR without multiple types of childhood trauma (CHR/Multiple Trauma Types -) were assessed by using chi-square and $t$ tests, as appropriate.

\section{Baseline differences in cognitive functioning}

Group differences in baseline cognitive functioning (combining nonsocial and social cognitive measures) between CHR/Multiple Trauma Types + and CHR/Multiple Trauma Types - participants were evaluated by using a repeated-measures analysis of covariance (RM-ANCOVA). The measures of cognitive functioning were the within-subject factor, and CHR subgroup (Multiple Trauma Types + or Multiple Trauma Types -) was the betweensubject factor. The RM-ANCOVAs were then repeated for each of the childhood trauma types individually. In addition, Multiple Trauma Types +/Multiple Trauma Types - comparisons for cognition were carried out for CHR individuals who converted to psychosis. All of the analyses adjusted for sex, baseline age, and years of education. The overall effect sizes (based on the comparison between CHR Multiple Trauma Types + and Multiple Trauma Types - groups) were computed and can be interpreted using the Cohen $d$ effect sizes conventions, described as 0.2 for small, 0.5 for medium, and 0.8 for large.

\section{Differences in cognitive change from baseline to time of psychotic conversion}

To examine differences in the patterns of cognitive change over time between CHR psychotic converters with and without a history of multiple childhood traumas, linear mixed models were carried out including baseline cognition and follow-up cognition (at time of psychotic conversion) scores. Covariates were sex, baseline age, and years of education. All of the analyses were performed using STATA/MP 15.0 (StataCorp, 2017) software.

\section{Results}

Group comparisons of sociodemographic and clinical characteristics

CHR vs. HC

The study sample consisted of 626 CHR individuals $(43.6 \%$ females) and $279 \mathrm{HC}$ participants (49.5\% females), with ages that ranged from 12 to 35 years. For the CHR group, mean age $=18.5$ $(S D=4.2)$; for the HC group, mean age $=19.8(S D=4.7)$. All sociodemographic and clinical characteristics as well as frequencies of trauma exposures for the $\mathrm{HC}$ and CHR subgroups (Multiple Trauma Types +/Present; Multiple Trauma Types -/Absent) are presented in Tables 1 and 2. As shown in our previous publications, HCs performed better across social (see Piskulic et al., 2016; Barbato et al., 2015) and nonsocial (Seidman et al., 2016) cognitive measures than the CHR group did.

CHR/Multiple Trauma Types + vs. CHR/Multiple Trauma Types The CHR subgroups (Multiple Trauma Types +/Multiple Trauma Types -) differed in sex distribution, with more females in the Multiple Trauma Types + group. The individuals with childhood trauma were also slightly older than those without (Table 1). Also, there was a statistically significant difference found in severity of current symptomatology between the two groups, with the CHR/ Multiple Trauma Types + group reporting more severe positive symptoms and general symptoms (see Table 1). Seventy-four individuals $(11.8 \%)$ with available baseline cognition data made a transition to a psychosis within a two-year period. Forty-five converters (7.2\% of CHR sample) had both baseline and follow-up data available and were included in the cognitive change analyses. The CHR converters with follow-up cognitive data did not differ on demographic variables from those without (see Supplemental Material, Table S2). Psychotic conversion rates and average number of days to transition were comparable between the trauma subgroups.

\section{Baseline cognitive functioning: CHR/Multiple Trauma Types + vs. CHR/Multiple Trauma Types -}

The baseline standardized $z$-scores for cognitive functioning in the CHR Trauma subgroups (Multiple Trauma Types + /Multiple Trauma Types -) are displayed in Figure 1 (for raw scores see Supplemental Material, Table S.1). Overall, there was a trend for better performance of CHR individuals with multiple types of childhood trauma across cognitive domains compared with those with no/one type of childhood trauma, $\mathrm{F}(1,498)=$ $3.11, p=0.079$; Cohen $d=0.16$. For additional analyses, we also looked at the relationship between childhood trauma (Multiple Trauma Types + /Multiple Trauma Types -) and social and nonsocial domains separately (neither reached traditional statistical difference, see the Supplemental Materials).

Looking at each of the childhood trauma types individually (Trauma Present vs. Trauma Absent), there was a trend observed for better overall cognitive performance in CHR youth reporting history of psychological abuse, $\mathrm{F}(1,523)=3.29, p=0.070$; Cohen $d=0.17$, and emotional neglect, $\mathrm{F}(1,520)=3.08, p=0.080$; Cohen $d=0.17$, vs. those who did not report these types of traumatic experiences. No differences in cognitive performance were found for other types of abuse (physical, sexual) or bullying (all ps $>0.3)$. 
Table 1. Sociodemographic and clinical characteristics for CHR Trauma subgroups (Multiple Trauma Types +/Present; Multiple Trauma Types -/Absent) and healthy controls (HC)

\begin{tabular}{|c|c|c|c|c|c|c|c|c|}
\hline & \multicolumn{5}{|c|}{$\mathrm{CHR}$} & \multicolumn{3}{|c|}{$\mathrm{HC}$} \\
\hline & Multiple Trauma Types (-) & Multiple Trauma Types (+) & Total & $\begin{array}{c}\text { Statistical } \\
\text { analysis } \\
\text { (between } \\
\text { Trauma } \\
+/-)\end{array}$ & $p$ value & & $\begin{array}{c}\text { Statistical } \\
\text { analysis } \\
\text { (between HC } \\
\text { and CHR } \\
\text { groupcombined: } \\
\text { Trauma+/-) }\end{array}$ & $p$ value \\
\hline \multicolumn{9}{|l|}{ Sociodemographics } \\
\hline Total $N(\%)$ & $333(53.2)$ & $293(46.8)$ & $626(100.0)$ & $\mathrm{n} / \mathrm{a}$ & $\mathrm{n} / \mathrm{a}$ & $279(100.0)$ & $\mathrm{n} / \mathrm{a}$ & $\mathrm{n} / \mathrm{a}$ \\
\hline \multicolumn{9}{|l|}{$\operatorname{Sex}(N, \%)$} \\
\hline Female & $112(41.0)$ & $161(59.0)$ & $353(100.0)$ & $\chi^{2}=14.69$ & $<0.001$ & $138(49.5)$ & $\chi^{2}=3.53$ & 0.060 \\
\hline Male & $221(62.6)$ & $132(37.4)$ & $273(100.0)$ & & & $141(50.5)$ & & \\
\hline Age $(M, S D)$ & $18.1(4.0)$ & $19.2(4.5)$ & $18.5(4.2)$ & $t=3.31$ & 0.001 & $19.8(4.7)$ & $t=4.12$ & $<0.001$ \\
\hline $\begin{array}{l}\text { Education (in } \\
\text { years) }(M, S D)\end{array}$ & $11.2(3.0)$ & $11.5(2.6)$ & $11.3(2.8)$ & $t=-1.59$ & 0.112 & $12.7(3.6)$ & $t=6.67$ & $<0.001$ \\
\hline \multicolumn{9}{|c|}{ Clinical characteristics } \\
\hline \multicolumn{9}{|c|}{ Baseline SOPS $(M, S D)$} \\
\hline Positive & $11.4(3.7)$ & $12.3(4.0)$ & $11.9(3.8)$ & $t=-2.83$ & 0.005 & $\mathrm{n} / \mathrm{a}$ & $\mathrm{n} / \mathrm{a}$ & $\mathrm{n} / \mathrm{a}$ \\
\hline Negative & $11.8(6.0)$ & $11.8(6.7)$ & $11.9(6.1)$ & $t=0.017$ & 0.987 & $\mathrm{n} / \mathrm{a}$ & $\mathrm{n} / \mathrm{a}$ & $\mathrm{m} / \mathrm{a}$ \\
\hline Disorganization & $4.9(3.2)$ & $5.3(3.0)$ & $5.2(3.2)$ & $t=-1.70$ & 0.089 & $\mathrm{n} / \mathrm{a}$ & $\mathrm{n} / \mathrm{a}$ & $\mathrm{n} / \mathrm{a}$ \\
\hline General & $8.6(4.3)$ & $10.0(4.1)$ & $9.1(4.3)$ & $t=-4.33$ & $<0.001$ & $\mathrm{n} / \mathrm{a}$ & $\mathrm{n} / \mathrm{a}$ & $\mathrm{n} / \mathrm{a}$ \\
\hline $\begin{array}{l}\text { Converted to } \\
\text { psychosis }\end{array}$ & $34(10.2 \%$ of CHR Trauma -$)$ & $40(13.7 \%$ of CHR Trauma +$)$ & $74(11.8 \%$ of total $\mathrm{CHR})$ & $\chi^{2}=1.77$ & 0.183 & $\mathrm{n} / \mathrm{a}$ & $\mathrm{n} / \mathrm{a}$ & $\mathrm{n} / \mathrm{a}$ \\
\hline $\begin{array}{l}\text { Days to psychotic } \\
\text { conversion }(M, S E)\end{array}$ & $253.2(42.4)$ & $307.1(46.0)$ & $288.4(42.4)$ & $t=-0.85$ & 0.398 & $\mathrm{n} / \mathrm{a}$ & $\mathrm{n} / \mathrm{a}$ & $\mathrm{n} / \mathrm{a}$ \\
\hline
\end{tabular}

Note: CHR, Clinical-High-Risk group; HC, Healthy Controls; SD, Standard Deviation; SE, Standard Error; SOPS, Scale of Psychosis-Risk Symptoms; $n / a$, not applicable. 
Table 2. Frequencies of trauma exposure for CHR Trauma subgroups (+/Present; -/Absent) and healthy controls (HC)

\begin{tabular}{|c|c|c|c|}
\hline \multicolumn{4}{|c|}{ Trauma exposure } \\
\hline \multirow[b]{2}{*}{ Trauma type } & \multicolumn{2}{|c|}{$\mathrm{CHR}$} & \multirow{2}{*}{$\begin{array}{c}\mathrm{HC} \\
+/ \text { Present } N(\%)\end{array}$} \\
\hline & -/Absent $N(\%)$ & +/Present $N(\%)$ & \\
\hline Any trauma & $143(22.8)$ & $483(77.2)$ & $86(39.1)^{\star \star \star}$ \\
\hline $\begin{array}{l}2 \text { or more } \\
\text { types of trauma }\end{array}$ & $333(53.2)$ & $293(46.8)$ & $23(10.5)^{\star \star \star}$ \\
\hline $\begin{array}{l}\text { Emotional } \\
\text { neglect }\end{array}$ & 371 (57.3) & $276(42.7)$ & $17(7.7)^{\star \star \star}$ \\
\hline $\begin{array}{l}\text { Psychological } \\
\text { abuse }\end{array}$ & $416(64.2)$ & $232(35.8)$ & 14. $(6.3)^{\star \star \star}$ \\
\hline Physical abuse & $493(76.7)$ & $150(23.3)$ & $11(4.9)^{\star \star \star}$ \\
\hline Sexual abuse & $550(85.7)$ & $92(14.3)$ & $3(1.4)^{\star \star \star}$ \\
\hline Bullying & $250(38.6)$ & $397(61.4)$ & $78(35.1)^{\star \star \star}$ \\
\hline
\end{tabular}

Note: $\mathrm{CHR}$, Clinical-High-Risk group; $\mathrm{HC}$, Healthy Controls; asterisks indicate the statistically significant differences between the HC and CHR groups (combined Trauma+/-), ${ }^{*} p<0.05$, ${ }^{\star \star} p<0.01,{ }^{\star \star \star} p<0.001$.

\section{Baseline cognitive functioning in CHR converters, as a function of trauma history}

Within CHR converters only, there was no significant difference in cognitive performance between individuals with a history of multiple types of trauma and those who reported no/one type of childhood trauma $(p=0.6)$. Statistical information for each of the cognitive domains is presented in the supplemental materials (Table S3).

\section{Cognitive changes in CHR-converters, as a function of multiple trauma types history}

Linear mixed models showed no significant differences in change in cognitive functioning over time between those who reported multiple types of childhood trauma and those who did not. For cognitive trajectories/changes in scores for each of the cognitive domains split by trauma subgroups, see Figure 3.

\section{Discussion}

To our knowledge, this is the first study to date to examine differences in cognitive functioning and cognitive change over time in youth at clinical high risk for psychosis with and without childhood trauma. The results indicate that among the CHR group, those who reported a history of multiple types of childhood trauma tended to show better overall cognitive performance than individuals without multiple types of childhood trauma did. In particular, this trend was observed for CHR individuals reporting psychological abuse and emotional neglect vs. those who did not report these types of traumatic events. A history of multiple types of childhood trauma was not associated with a higher rate of psychotic conversion or with greater cognitive change in CHR converters with multiple trauma types than those without.

The high prevalence of adverse childhood events in our CHR group is consistent with our expectations, as childhood victimization has been widely recognized to be associated with increased levels of subclinical (Arseneault et al., 2011; Kraan et al., 2015; Varese et al., 2012) and clinical psychosis (Bendall et al., 2008; Fisher et al., 2010; Morgan \& Fisher, 2007) in both child (Arseneault et al., 2011) and adult (Fisher et al., 2010) populations.

Our findings are generally consistent with those of Campbell et al. (2013), where first-episode psychosis patients who reported childhood trauma had better premorbid IQ than those without early trauma. That is, our results are inconsistent with findings from general population studies (where people with a history of trauma are generally found to have worse cognitive functioning than their peers); moreover the cognitive performance of $\mathrm{CHR}$ individuals with multiple types of trauma was trending in the opposite direction. Although this trend was not upheld in the subgroup of individuals who converted to psychosis (possibly due to limited power), the magnitude of the difference in cognitive performance (for some measures) between individuals reporting multiple types of trauma and those without was actually larger.

Similar patterns were observed for nonsocial and social cognition. Our findings are unexpected for social cognition, as childhood trauma has been associated previously with deficits in the ability to recognize one's own affect and that of others (Lysaker et al., 2011). Nevertheless, a recent study by Trauelsen et al. (2019) found that in patients with first-episode psychosis, individuals who reported childhood trauma displayed better metacognitive abilities than those without such experiences.

The (trending) better cognitive functioning in CHR individuals with a history of childhood trauma may point towards differential (not mutually exclusive) pathways that lead to clinical-high-risk states and potentially psychosis: one that is primarily triggered by external stressors and one potentially representing a more neurodevelopmental/genetic pathway. In the first pathway, childhood trauma may serve as a substantial environmental stressor. It has now been well established that environmental stress is an important factor in the development of psychosis (Bendall et al., 2008; Cannon et al., 2002; Kraan et al., 2015; Morgan \& Fisher, 2007; Read, Perry, Moskowitz, \& Connolly, 2001; Tienari et al., 1994; Varese et al., 2012). Multiple studies suggest that early trauma can lead to neurochemical abnormalities, such as dysregulations of the hypothalamuspituitary-adrenal axis (HPA; Corcoran et al., 2003; Walker \& Diforio, 1997) and dopaminergic activity (Howes, McCutcheon, Owen, \& Murray, 2017). Consequently, childhood trauma can have an enduring effect on adult stress sensitivity (the stress-vulnerability model; Nuechterlein \& Dawson, 1984; Zubin, 1977), which may underlie more severe psychopathology, including psychosis. Findings by Myin-Germeys et al. (2002) showed no positive association between (nonsocial) cognitive deficits and stress sensitivity. Instead their results showed no association or a reverse association for some cognitive domains, which may provide further support for a stress versus genetic neurodevelopmental pathway (where premorbid cognitive deficits are often apparent). The second pathway may represent a stronger genetic vulnerability to psychosis (Agnew-Blais \& Seidman, 2013; Cornblatt, Obuchowski, Roberts, Pollack, \& Erlenmeyer-Kimling, 1999; Harvey, Walker, \& Wielgus, 1986; Snitz, Macdonald, \& Carter, 2006) because those who did not experience childhood victimization displayed more severe cognitive dysfunction. Furthermore, this "genetic vulnerability" pathway to psychosis might reflect more prominent structural brain abnormalities (Cannon et al., 1993) that are possibly already evident at birth (Weinberger, 1987). 


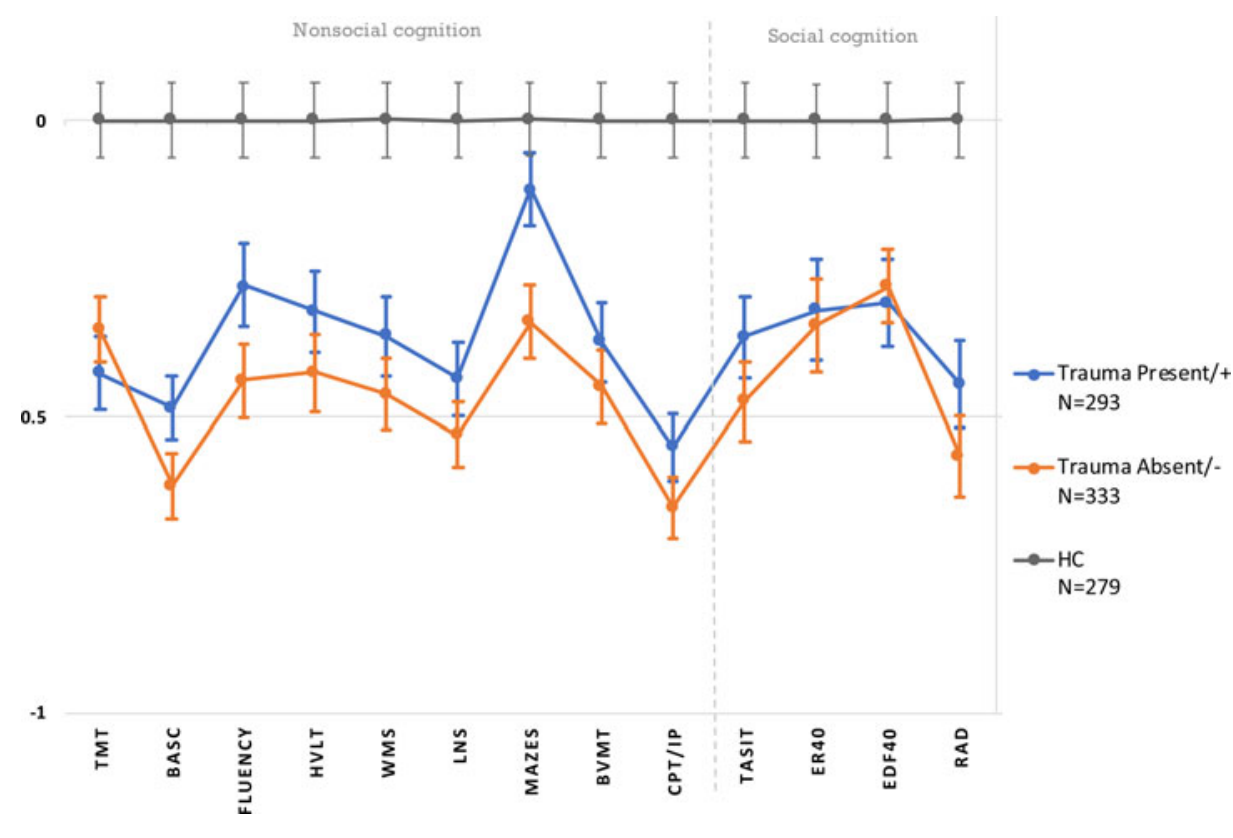

Figure 1. Baseline standardized $z$-scores ( $y$-axis) and standard errors (indicated by the bars) across cognitive assessments for the CHR trauma subgroups (Multiple Trauma Types +/Present; Multiple Trauma Types -/Absent), standardized with healthy control (HC) means (and SDs) to convert to $z$-scores, adjusted for sex, baseline age, and years of education. Symbol Coding: TMT, Trail Making Test; BACS, Brief Assessment of Cognition in Schizophrenia; Fluency, Category Fluency; HVLT, Hopkins Verbal Learning Test-Revised; WMS, Wechsler Memory Scale-Spatial Span; LNS, Letter Number Span; Mazes, Neuropsychological Assessment Battery-Mazes; BVMT, Brief Visuospatial Memory Test-Revised; CPT/IP, Continuous Performance Test-Identical Pairs; TASIT, The Awareness of Social Inference Test; ER40, The Penn Emotion Recognition task; EDF40, Penn Emotion Differentiation task; RAD, Relationship Across Domains.

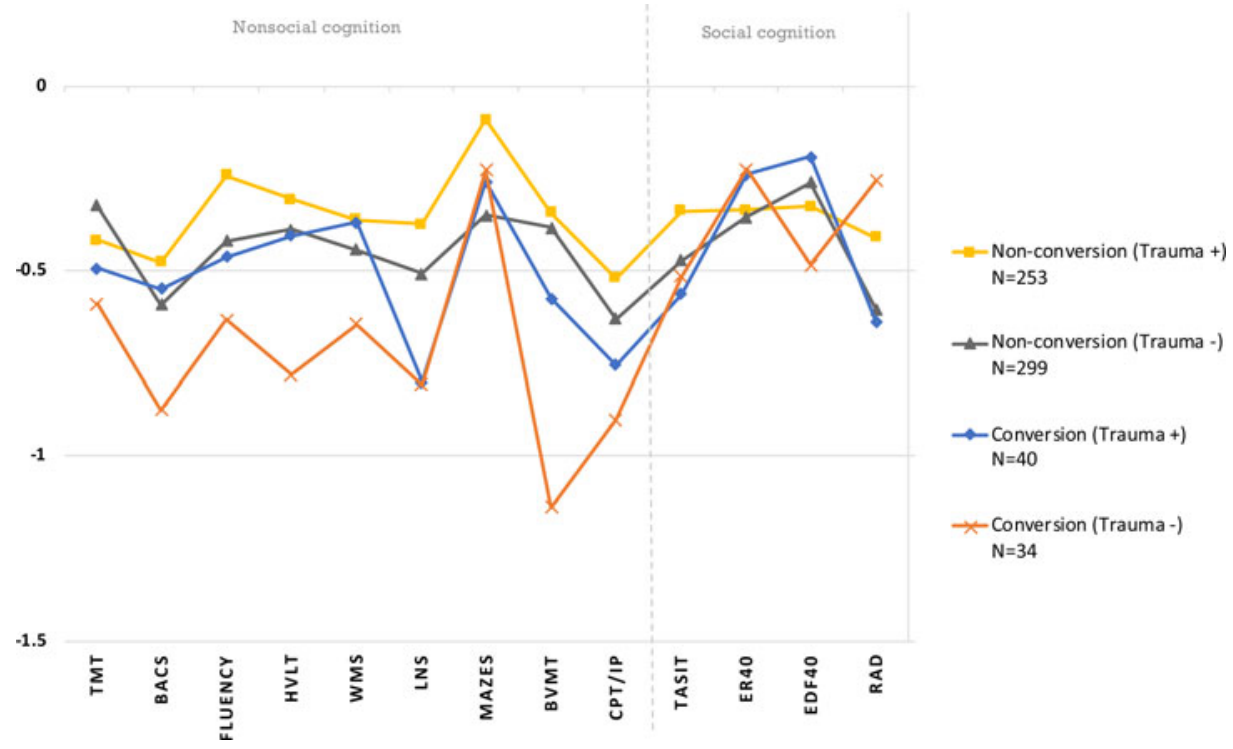

Figure 2. Baseline standardized $z$-scores ( $y$-axis) across cognitive assessments for the CHR subgroups (Converters and Nonconverters to full-threshold psychosis), split by childhood trauma (Multiple Trauma Types +/Present; Multiple Trauma Types -/Absent) and standardized with healthy control (HC) means (and SDs) to convert to $z$-scores, adjusted for sex, baseline age, and years of education. Symbol Coding: TMT, Trail Making Test; BACS, Brief Assessment of Cognition in Schizophrenia; Fluency, Category Fluency; HVLT, Hopkins Verbal Learning Test-Revised; WMS, Wechsler Memory Scale-Spatial Span; LNS, Letter Number Span; Mazes, Neuropsychological Assessment Battery-Mazes; BVMT, Brief Visuospatial Memory Test-Revised; CPT/IP, Continuous Performance Test-Identical Pairs; TASIT, The Awareness of Social Inference Test; ER40, The Penn Emotion Recognition task; EDF40, Penn Emotion Differentiation task; RAD, Relationship Across Domain.
Baseline symptom profiles and sociodemographic characteristics of CHR trauma subgroups (Multiple Trauma Types + and Multiple Trauma Types-) may offer more insight into distinct underlying mechanisms that predispose individuals to psychosis. Previous work has suggested distinct symptom and sociodemographic profiles in individuals with a predominantly stress-related pathway to psychosis. And consistent with previous findings relating to a stress-related pathway (Myin-Germeys et al., 2007), CHR individuals with a history of multiple types of childhood trauma in our sample were more likely to be female and presented with more positive psychotic symptoms and general psychopathology.

An alternative explanation of the findings of a tendency toward better cognitive abilities in CHR individuals with history of multiple types of childhood trauma (compared with those with no/one type of childhood trauma) is that CHR individuals with better cognition were better able to recall traumatic events. Unfortunately, our study did not evaluate long-term memory (delayed recall), so we cannot directly address this. Additionally, better cognitive performance in the trauma-positive (defined as Multiple Trauma Types +) subgroup could be contributed to Type 1 errors (false positives), but the consistent nature of the findings across cognitive measures makes this unlikely.

Looking at cognitive changes over time within individuals converting to psychosis, we observed no statistically significant differences in those with and without history of multiple trauma types. Interestingly, the group with multiple types of childhood trauma showed slightly (but not significantly) higher baseline nonsocial cognition scores without further decline on domains like working memory and visual learning, which was not evident for individuals who were not exposed to multiple types of adverse childhood 


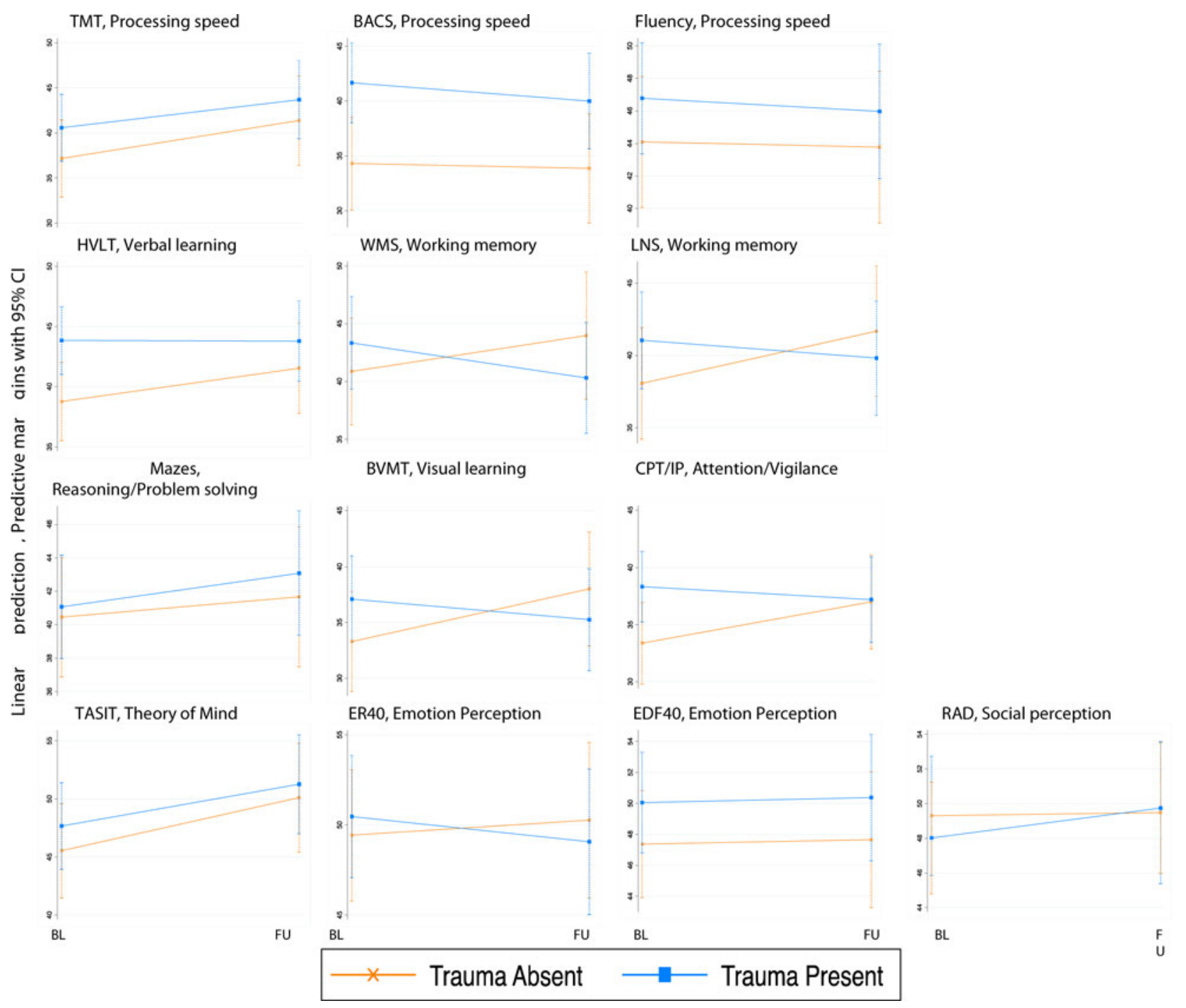

Figure 3. Cognitive changes (T-scores) of cognitive functioning for CHR individuals who converted to full-blown psychosis by Trauma subgroups (Multiple Trauma Types +/Present; Multiple Trauma Types -/Absent); BL represents baseline and FU is follow-up time of conversion to full-threshold psychosis. Symbol Coding: TMT, Trail Making Test; BACS, Brief Assessment of Cognition in Schizophrenia; Fluency, Category Fluency; HVLT, Hopkins Verbal Learning Test-Revised; WMS, Wechsler Memory Scale-Spatial Span; LNS, Letter Number Span; Mazes, Neuropsychological Assessment Battery-Mazes; BVMT, Brief Visuospatial Memory Test-Revised; CPT/ IP, Continuous Performance Test,-Identical Pairs; TASIT, The Awareness of Social Inference Test; ER40; The Penn Emotion Recognition task; EDF40, Penn Emotion Differentiation task; RAD, Relationship Across Domains.

experiences. Nevertheless, more longitudinal research is required (with longer follow-up periods) to truly unravel the trajectories of cognitive function in this population over time.

Also, it is important to highlight that the two proposed theories/pathways to clinical high-risk states and psychosis are not the only potential mechanisms underlying these clinical phenotypes. The literature shows substantial heterogeneity and complexity of factors that predispose individuals to psychosis (Radua et al., 2018), with some yet to be elucidated. Moreover, further studies are needed to untangle and validate these different pathways to psychosis because they may not necessarily be mutually exclusive and they may also occur during different developmental periods (Davis et al., 2016).

\section{Limitations and recommendations for future research}

The current results need to be considered in light of several limitations. First, it is important to note that the differences in cognitive functioning between multiple trauma types-positive and multiple trauma types-negative CHR individuals were small (effect size of 0.16) and only trending towards significance. Second, childhood trauma was only defined as "present" or "absent," with no differentiation of severity, frequency, and age/ developmental timing of trauma occurrence, all of which are significant factors that are associated with psychotic symptomatology (Fisher et al., 2010). Future studies would benefit from carefully mapping these various characteristics of childhood trauma (timing, chronicity, and severity) when exploring cognition among clinical-high-risk groups. Also, polyvictimization (i.e., exposure to multiple forms of victimization) has been widely reported (Dong et al., 2004; Kessler et al., 2010) and considered in our study. Yet, we have not assessed the interrelationships among multiple forms of adverse childhood experiences, which makes it difficult to differentiate which combination of traumas has the highest effect on cognitive functioning. Additionally, we were not able to account for multiple incidences of the same trauma 
types (i.e., complete victimization profiles), a largely unaddressed issue in studies of child victimization (Finkelhor et al. 2007). The focus on incidences of different childhood trauma types may have hindered the identification of the most victimized CHR individuals in our study (i.e., those with chronic exposure to one particular trauma type; Turner et al., 2010). In a similar vein, certain types of childhood trauma (e.g., sexual abuse; Thompson et al., 2014) have showed the most robust association with psychosis, but in our study individuals with a single occurrence of these types of trauma might have been included in the trauma-negative group (no/one type of trauma vs. multiple types of trauma). Nevertheless, our secondary analyses confirmed that the association that was observed between childhood trauma and cognition in our study did not appear to be driven by sexual abuse. Third, the main childhood trauma measure that was used in this study (the Childhood Trauma and Abuse Scale; Janssen et al., 2004) was based on retrospective self-report. However, although several concerns have been raised with regard to retrospective reporting (amnesia [Howe \& Courage, 1993], moodcongruent recall [Bower, 1981], and the reconstructive nature of memory [Schacter, 1999]), it has been shown that patients with a psychotic disorder report past abuse reliably (Fisher et al., 2011). Fourth, the types of traumas that were considered for our analyses paint only a partial picture of the adverse environment to which the individual is exposed, which calls for inclusion of other factors that have been shown to influence cognition in clinical high risk groups (e.g., domestic violence [Koenen et al., 2003]), or lifetime revictimization [Widom, Czaja, \& Dutton, 2008]). Moreover, childhood trauma may be confounded by or related to socioeconomic status (Hackman \& Farah, 2009), lack of stimuli or undernutrition (Burchinal, Vernon-Feagans, Cox, \& Key Family Life Project, 2008), and insecure attachment style (Ding, Xu, Wang, Li, \& Wang, 2014) among others. Fifth, the number of CHR psychotic converters was low (11.8\% of the CHR sample, $N=74$ ) yet comparable to other CHR samples (Fusar-Poli et al., 2016), which precluded a more fine-grained analysis (e.g., sex differences in cognitive change over time). Finally, the assessment of cognitive functioning in our study was limited to two points (baseline and follow-up at psychotic conversion). A longer follow-up duration would allow for a measurement of the stability of cognitive functioning over time in those who do and do not report childhood trauma.

\section{Conclusion}

This study demonstrated that among individuals at clinical high risk of psychosis, there was a trend for better cognitive performance in those with multiple types of childhood trauma than among those who reported no/one type of trauma. In particular, this trend was observed for CHR individuals who reported psychological abuse and emotional neglect when they were compared with those who did not report these types of trauma. These findings lead us to speculate that CHR individuals with and without childhood trauma follow different trajectories to clinical-high-risk states. More studies are needed to validate these different trajectories and fully unravel the complexity of mechanisms underlying the pathways to psychosis.

Supplementary Material. The supplementary material for this article can be found at https://doi.org/10.1017/S095457941900155X.

Financial Support. Dr. Velikonja received support from the Seaver Foundation; Dr. Velikonja is a Seaver Postdoctoral Research Fellow. Dr. Velthorst received support by a 2018 NARSAD Young Investigator Award from the Brain and Behavior Foundation and from the Seaver Foundation; Dr. Velthorst is a Seaver Faculty Scholar. This study was also supported by the National Institute of Mental Health (grant U01MH081984 to Dr. Addington; grants U01 MH081928, P50 MH080272, and Commonwealth of Massachusetts SCDMH82101008006 to Dr. Seidman; grants R01 MH60720, U01 MH082022, and K24 MH76191 to Dr. Cadenhead; grant MH081902 and U01MH081902 to Dr. Cannon; grant P50 MH066286 to Dr. Bearden; grant U01MH082004-01A1 to Dr. Perkins; grant U01MH081988 to Dr. Walker; grant U01MH082022 to Dr. Woods; and grant UO1 MH081857 to Dr. Cornblatt) as well as a gift from One Mind to Dr. Bearden.

Conflict of Interest. None reported.

\section{References}

Aas, M., Dazzan, P., Fisher, H. L., Morgan, C., Morgan, K., Reichenberg, A., Zanelli, J., Fearon, P., Jones, P.B., \& Pariante, C. M. (2011). Childhood trauma and cognitive function in first-episode affective and non-affective psychosis. Schizophrenia Research, 129, 12-19. doi:10.1016/ j.schres.2011.03.017

Addington, J., Cadenhead, K. S., Cornblatt, B. A., Mathalon, D. H., McGlashan, T. H., Perkins, ... Cannon, T. D. (2012). North American Prodrome Longitudinal Study (NAPLS 2): Overview and recruitment. Schizophrenia Research, 142, 77-82. doi:10.1016/j.schres.2012.09.012

Addington, J., Liu, L., Buchy, L., Cadenhead, K. S., Cannon, T. D., Cornblatt, B. A., ... McGlashan, T. H. (2015). North American Prodrome Longitudinal Study (NAPLS 2): The prodromal symptoms. Journal of Nervous and Mental Disease, 203, 328-335. doi:10.1097/NMD.0000000000000290

Addington, J., Stowkowy, J., Cadenhead, K. S., Cornblatt, B. A., McGlashan, T. H., Perkins, D., ... Cannon, T. D. (2013). Early traumatic experiences in those at clinical high risk for psychosis. Early Intervention in Psychiatry, 7, 300-305. doi:10.1111/eip.12020

Agnew-Blais, J., \& Seidman, L. J. (2013). Neurocognition in youth and young adults under age 30 at familial risk for schizophrenia: A quantitative and qualitative review. Cognitive Neuropsychiatry, 18, 44-82. doi:10.1080/ 13546805.2012.676309

Arseneault, L., Cannon, M., Fisher, H. L., Polanczyk, G., Moffitt, T. E., \& Caspi, A. (2011). Childhood trauma and children's emerging psychotic symptoms: A genetically sensitive longitudinal cohort study. American Journal of Psychiatry, 168, 65-72. doi:10.1176/appi.ajp.2010.10040567

Barbato, M., Colijn, M. A., Keefe, R. S., Perkins, D. O., Woods, S. W., Hawkins, K. A., ... Addington, J. (2013). The course of cognitive functioning over six months in individuals at clinical high risk for psychosis. Psychiatry Research, 206, 195-199. doi:10.1016/j.psychres.2012.10.013

Barbato, M., Liu, L., Cadenhead, K. S., Cannon, T. D., Cornblatt, B. A., McGlashan, T. H., ... Addington, J. (2015). Theory of mind, emotion recognition and social perception in individuals at clinical high risk for psychosis: Findings from the NAPLS-2 cohort. Schizophrenia Research: Cognition, 2, 133-139. doi:10.1016/j.scog.2015.04.004

Beers, S. R., \& De Bellis, M. D. (2002). Neuropsychological function in children with maltreatment-related posttraumatic stress disorder. American Journal of Psychiatry, 159, 483-486. doi:10.1176/appi.ajp.159.3.483

Bendall, S., Jackson, H. J., Hulbert, C. A., \& McGorry, P. D. (2008). Childhood trauma and psychotic disorders: A systematic, critical review of the evidence. Schizophrenia Bulletin, 34, 568-579. doi:10.1093/schbul/sbm121

Benedict, R. H. B., Schretlen, D., Groninger, L., \& Brandt, J. (1998). The Hopkins Verbal Learning Test-Revised: Normative data and analysis of interform and test-retest reliability. Clinical Neuropsychologist, 12, 43-55.

Benedict, R. H., Schretlen, D., Groninger, L., Dobraski, M., Sphritz, B. (1996). Revision of the Brief Visuospatial Memory Test: Studies of normal performance, reliability, and validity. Psychological Assessment, 8, 145-153.

Bora, E., \& Murray, R. M. (2014). Meta-analysis of cognitive deficits in ultrahigh risk to psychosis and first-episode psychosis: Do the cognitive deficits progress over, or after, the onset of psychosis? Schizophrenia Bulletin, 40, 744-755. doi:10.1093/schbul/sbt085

Bower, G. H. (1981). Mood and memory. American Psychologist, 36, 129-148. Burchinal, M., Vernon-Feagans, L., Cox, M., \& Key Family Life Project, I. (2008). Cumulative social risk, parenting, and infant development in rural 
low-income communities. Parenting: Science and Practice, 8, 41-69. doi:10.1080/15295190701830672

Campbell CB, S., Shannon, S., Hoy, K., Rushe, T., Cooper, S., \& Mulholland, C. (2013). The relationship between childhood trauma and neuropsychological functioning in first episode psychosis. Psychosis, 5, 48-59.

Cannon, M., Caspi, A., Moffitt, T. E., Harrington, H., Taylor, A., Murray, R. M., \& Poulton, R. (2002). Evidence for early-childhood, pan-developmental impairment specific to schizophreniform disorder: Results from a longitudinal birth cohort. Archives of General Psychiatry, 59, 449-456.

Cannon, T. D., Mednick, S. A., Parnas, J., Schulsinger, F., Praestholm, J., \& Vestergaard, A. (1993). Developmental brain abnormalities in the offspring of schizophrenic mothers. I. Contributions of genetic and perinatal factors. Archives of General Psychiatry, 50, 551-564.

Corcoran, C., Walker, E., Huot, R., Mittal, V., Tessner, K., Kestler, L., \& Malaspina, D. (2003). The stress cascade and schizophrenia: Etiology and onset. Schizophrenia Bulletin, 29, 671-692.

Cornblatt, B. A., \& Erlenmeyer-Kimling, L. (1985). Global attentional deviance as a marker of risk for schizophrenia: Specificity and predictive validity. Journal of Abnormal Psychology, 94, 470-486.

Cornblatt, B., Obuchowski, M., Roberts, S., Pollack, S., \& Erlenmeyer-Kimling, L. (1999). Cognitive and behavioral precursors of schizophrenia. Dev Psychopathol, 11, 487-508.

Dauvermann, M. R., \& Donohoe, G. (2019). The role of childhood trauma in cognitive performance in schizophrenia and bipolar disorder-A systematic review. Schizophrenia Research: Cognition, 16, 1-11. doi:10.1016/ j.scog.2018.11.001

Davis, J., Eyre, H., Jacka, F. N., Dodd, S., Dean, O., McEwen, S., ... Berk, M. (2016). A review of vulnerability and risks for schizophrenia: Beyond the two hit hypothesis. Neuroscience \& Biobehavioral Reviews, 65, 185-194. doi:10.1016/j.neubiorev.2016.03.017

Ding, Y. H., Xu, X., Wang, Z. Y., Li, H. R., \& Wang, W. P. (2014). The relation of infant attachment to attachment and cognitive and behavioural outcomes in early childhood. Early Human Devevelopment, 90, 459-464. doi:10.1016/ j.earlhumdev.2014.06.004

Dong, M., Anda, R. F., Felitti, V. J., Dube, S. R., Williamson, D. F., Thompson, T. J., ... Giles, W. H. (2004). The interrelatedness of multiple forms of childhood abuse, neglect, and household dysfunction. Child Abuse \& Neglect, 28, 771-784. doi:10.1016/j.chiabu.2004.01.008

Dozier, M., Stovall-McClough, K. C., \& Albus, K. E. (2008). Attachment and psychopathology in adulthood. In J. C. P. R. Shave (Ed.), Handbook of attachment: Theory, research, and clinical applications (pp. 718-744). New York: Guilford Press.

Finkelhor, D., Ormrod, R.K., Turner, H.A. (2007). Poly-victimization: A neglected component in child victimization. Child Abuse \& Neglect, 31, $7-26$.

First, M. S. R., Gibbon, M., Williams, B., \& Williams, J.B.W. (1995). Structured Clinical Interview for DSM-IV Axis I Disorders, Patient Edition. New York: Biometrics Research Department, New York State Psychiatric Institute.

Fisher, H. L., Craig, T. K., Fearon, P., Morgan, K., Dazzan, P., Lappin, J., Hutchinson, G., ... Morgan, C. (2011). Reliability and comparability of psychosis patients' retrospective reports of childhood abuse. Schizophrenia Bulletin, 37(3), 546-553. doi:10.1093/schbul/sbp103

Fisher, H. L., Jones, P. B., Fearon, P., Craig, T. K., Dazzan, P., Morgan, K., Hutchinson, G., ... Morgan, C. (2010). The varying impact of type, timing and frequency of exposure to childhood adversity on its association with adult psychotic disorder. Psychological Medicine, 40, 1967-1978. doi:10.1017/S0033291710000231

Fiske, A. P. (1991). Structures of social life: The four elementary forms of human relations. New York: Free Press.

Fusar-Poli, P., Bonoldi, I., Yung, A. R., Borgwardt, S., Kempton, M. J., Valmaggia, L., ... McGuire, P. (2012). Predicting psychosis: Meta- analysis of transition outcomes in individuals at high clinical risk. Archives of General Psychiatry, 69, 220-229.

Fusar-Poli, P., Cappucciati, M., Borgwardt, S., Woods, S. W., Addington, J., Nelson, B., ... McGuire, P.K. (2016). Heterogeneity of psychosis risk within individuals at clinical high risk: A meta-analytical stratification. JAMA Psychiatry, 73, 113-120. doi:10.1001/jamapsychiatry.2015.2324
Fusar-Poli, P., Deste, G., Smieskova, R., Barlati, S., Yung, A. R., Howes, O., ... Borgwardt, S. (2012). Cognitive functioning in prodromal psychosis: A meta-analysis. Archives of General Psychiatry, 69, 562-571. doi:10.1001/ archgenpsychiatry.2011.1592

Giuliano, A. J., Li, H., Mesholam-Gately, R. I., Sorenson, S. M., Woodberry, K. A., \& Seidman, L. J. (2012). Neurocognition in the psychosis risk syndrome: A quantitative and qualitative review. Current Pharmaceutical Design, 18, 399-415.

Goghari, V. M., \& Sponheim, S. R. (2013). More pronounced deficits in facial emotion recognition for schizophrenia than bipolar disorder. Comprehensive Psychiatry, 54, 388-397. doi:10.1016/ j.comppsych.2012.10.012

Gold, J. M., Carpenter, C., Randolph, C., Goldberg, T. E., \& Weinberger, D. R. (1997). Auditory working memory and Wisconsin Card Sorting Test performance in schizophrenia. Archives of General Psychiatry, 54, 159-165.

Green, M. F., Bearden, C. E., Cannon, T. D., Fiske, A. P., Hellemann, G. S., Horan, W. P., ... Neicherlein, K.H. (2012). Social cognition in schizophrenia, Part 1: Performance across phase of illness. Schizophrenia Bulletin, 38, 854-864. doi:10.1093/schbul/sbq171

Gur, R. C., Sara, R., Hagendoorn, M., Marom, O., Hughett, P., Macy, L., ... Gur, R. E. (2002). A method for obtaining 3-dimensional facial expressions and its standardization for use in neurocognitive studies. Journal of Neuroscience Methods, 115, 137-143.

Hackman, D. A., \& Farah, M. J. (2009). Socioeconomic status and the developing brain. Trends in Cognitive Sciences, 13, 65-73. doi:10.1016/ j.tics.2008.11.003

Harvey, P. D., Walker, E., \& Wielgus, M. S. (1986). Psychological markers of vulnerability to schizophrenia: Research and future directions. Progressin Experimental Personality \& Psychopathology Research, 14, 231-267.

Hou, C. L., Xiang, Y. T., Wang, Z. L., Everall, I., Tang, Y., Yang, C., ... Jia, F. J. (2016). Cognitive functioning in individuals at ultra-high risk for psychosis, first-degree relatives of patients with psychosis and patients with firstepisode schizophrenia. Schizophrenia Research, 174, 71-76. doi:10.1016/ j.schres.2016.04.034

Howe, M. L., \& Courage, M. L. (1993). On resolving the enigma of infantile amnesia. Psychological Bulletin, 113, 305-326.

Howes, O. D., McCutcheon, R., Owen, M. J., \& Murray, R. M. (2017). The role of genes, stress, and dopamine in the development of schizophrenia. Biolological Psychiatry, 81, 9-20. doi:10.1016/j.biopsych.2016.07.014

Janssen, I., Krabbendam, L., Bak, M., Hanssen, M., Vollebergh, W., de Graaf, R., \& van Os, J. (2004). Childhood abuse as a risk factor for psychotic experiences. Acta Psychiatrica Scandinavica, 109, 38-45.

Keefe, R. S., Goldberg, T. E., Harvey, P. D., Gold, J. M., Poe, M. P., \& Coughenour, L. (2004). The Brief Assessment of Cognition in Schizophrenia: Reliability, sensitivity, and comparison with a standard neurocognitive battery. Schizophrenia Research, 68, 283-297. doi:10.1016/ j.schres.2003.09.011

Kelleher, I., Clarke, M. C., Rawdon, C., Murphy, J., \& Cannon, M. (2013) Neurocognition in the extended psychosis phenotype: Performance of a community sample of adolescents with psychotic symptoms on the MATRICS neurocognitive battery. Schizophrenia Bulletin, 39, 1018-1026. doi:10.1093/schbul/sbs086

Kelleher, I., Keeley, H., Corcoran, P., Ramsay, H., Wasserman, C., Carli, V., ... Cannon, M. (2013). Childhood trauma and psychosis in a prospective cohort study: Cause, effect, and directionality. American Journal of Psychiatry, 170, 734-741. doi:10.1176/appi.ajp.2012.12091169

Kern, R. S., Green, M. F., Fiske, A. P., Kee, K. S., Lee, J., Sergi, M. J., ... Nuechterlein, K. H. (2009). Theory of mind deficits for processing counterfactual information in persons with chronic schizophrenia. Psychological Medicine, 39, 645-654. doi:10.1017/S0033291708003966

Kessler, R. C., McLaughlin, K. A., Green, J. G., Gruber, M. J., Sampson, N. A., Zaslavsky, A. ... Williams, D. R. (2010). Childhood adversities and adult psychopathology in the WHO World Mental Health Surveys. British Journal of Psychiatry, 197, 378-385. doi:10.1192/bjp.bp.110.080499

Koenen, K. C., Moffitt, T. E., Caspi, A., Taylor, A., \& Purcell, S. (2003). Domestic violence is associated with environmental suppression of IQ in young children. Development and Psychopathology, 15, 297-311. 
Kohler, C. G., Bilker, W., Hagendoorn, M., Gur, R. E., \& Gur, R. C. (2000). Emotion recognition deficit in schizophrenia: Association with symptomatology and cognition. Biological Psychiatry, 48, 127-136.

Kohler, C. G., Richard, J. A., Brensinger, C. M., Borgmann-Winter, K. E., Conroy, C. G., Moberg, P. J., ... Calkins, M. E. (2014). Facial emotion perception differs in young persons at genetic and clinical high-risk for psychosis. Psychiatry Researchearch, 216, 206-212. doi:10.1016/ j.psychres.2014.01.023

Kraan, T., Velthorst, E., Smit, F., de Haan, L., \& van der Gaag, M. (2015). Trauma and recent life events in individuals at ultra high risk for psychosis: Review and meta-analysis. Schizophrenia Research, 161, 143-149. doi:10.1016/j.schres.2014.11.026

Lysaker, P.H., Gumley, A., Brune, M., Vanheule, S., Buck, K.D., Dimaggio, G. (2011). Deficits in the ability to recognize one's own affects and those of others: Associations with neurocognition, symptoms and sexual trauma amog persons with schizophrenia spectrum disorders. Consciousness and Cognition, 20, 1183-1192.

Malarbi, S., Abu-Rayya, H.M., Muscara, F., Stargatt, R. (2017) Neuropsychological functioning of childhood trauma and post-traumatic stress disorder: A meta-analysis. Neuroscience \& Biobehavioral Reviews, 72, 68-86.

Matheson, S. L., Shepherd, A. M., Pinchbeck, R. M., Laurens, K. R., \& Carr, V. J. (2013). Childhood adversity in schizophrenia: A systematic meta-analysis. Psychological Medicine, 43, 225-238. doi:10.1017/S0033291712000785

McDonald, S., Flanagan, S., Rollins, J., \& Kinch, J. (2003). TASIT: A new clinical tool for assessing social perception after traumatic brain injury. Journal of Head Trauma Rehabilitation, 18, 219-238.

McGlashan T, W. B., Woods, SW. (2010). The Psychosis Risk Syndrome: Handbook for Diagnosis and Follow-up. New York: Oxford University Press.

Mezzacappa, E., Kindlon, D., \& Earls, F. (2001). Child abuse and performance task assessments of executive functions in boys. Journal of Child Psychology and Psychiatry, 42, 1041-1048.

Miller, T. J., McGlashan, T. H., Rosen, J. L., Cadenhead, K., Cannon, T., Ventura, J., ... Woods, S.W. (2003). Prodromal assessment with the structured interview for prodromal syndromes and the scale of prodromal symptoms: Predictive validity, interrater reliability, and training to reliability. Schizophrenia Bulletin, 29, 703-715.

Miller, T.J., McGlashan, T.H., Rosen, J.L., Somjee, L., Markovich, P.J., Stein, K., \& Woods, S.W. (2002). Prospective diagnosis of the initial prodrome for schizophrenia based on the Structured Interview for Prodromal Syndromes: Preliminary evidence of interrater reliability and predictive validity. American Journal of Psychiatry, 159, 863-865.

Morgan, C., \& Fisher, H. (2007). Environment and schizophrenia: Environmental factors in schizophrenia: Childhood trauma-A critical review. Schizophrenia Bulletin, 33, 3-10. doi:10.1093/schbul/sbl053

Myin-Germeys, I., Krabbendam, L., Jolles, J., Delespaul, P. A., \& van Os, J. (2002). Are cognitive impairments associated with sensitivity to stress in schizophrenia? An experience sampling study. American Journal of Psychiatry, 159, 443-449. doi:10.1176/appi.ajp.159.3.443

Myin-Germeys, I., \& van Os, J. (2007). Stress-reactivity in psychosis: Evidence for an affective pathway to psychosis. Clinical Psychology Review, 27, 409424. doi:10.1016/j.cpr.2006.09.005

Navalta, C. P., Polcari, A., Webster, D. M., Boghossian, A., \& Teicher, M. H. (2006). Effects of childhood sexual abuse on neuropsychological and cognitive function in college women. Journal of Neuropsychiatry and Clinical Neurosciences, 18, 45-53. doi:10.1176/jnp.18.1.45

Nuechterlein, K., \& Dawson, M. E. (1984). A heuristic vulnerability-stress model of schizophrenia. Schizophrenia Bulletin, 10, 300-312.

Nuechterlein, K. H., Green, M. F., Kern, R. S., Baade, L. E., Barch, D. M., Cohen, J. D., ... Marder, S. R. (2008). The MATRICS Consensus Cognitive Battery, Part 1: Test selection, reliability, and validity. American Journal of Psychiatry, 165, 203-213. doi:10.1176/appi.ajp.2007.07010042

Piskulic, D., Liu, L., Cadenhead, K. S., Cannon, T. D., Cornblatt, B. A., McGlashan, T. H., Perkins, D.O., ... Addington, J. (2016). Social cognition over time in individuals at clinical high risk for psychosis: Findings from the NAPLS-2 cohort. Schizophrenia Research, 171, 176-181. doi:10.1016/ j.schres.2016.01.017

Radua, J., Ramella-Cravaro, V., Ioannidis, J. P. A., Reichenberg, A., Phiphopthatsanee, N., Amir, T., ... Fusar-Poli, P. (2018). What causes psychosis? An umbrella review of risk and protective factors. World Psychiatry, 17, 49-66. doi:10.1002/wps.20490

Read, J., Perry, B. D., Moskowitz, A., \& Connolly, J. (2001). The contribution of early traumatic events to schizophrenia in some patients: A traumagenic neurodevelopmental model. Psychiatry, 64, 319-345.

Reichenberg, A., Caspi, A., Harrington, H., Houts, R., Keefe, R. S., Murray, R. M., ... Moffitt, T. E. (2010). Static and dynamic cognitive deficits in childhood preceding adult schizophrenia: A 30-year study. American Journal of Psychiatry, 167, 160-169. doi:10.1176/appi.ajp.2009.09040574

Reitan Neuropsychology Laboratory (1944). Army Individual Test Battery, Manual of Directions and Scoring. Washington, DC: War Department, Adjunct General's Office.

Rokita, K. I., Dauvermann, M. R., \& Donohoe, G. (2018). Early life experiences and social cognition in major psychiatric disorders: A systematic review. European Psychiatry, 53, 123-133. doi:10.1016/ j.eurpsy.2018.06.006

Schacter, D. L. (1999). The seven sins of memory. Insights from psychology and cognitive neuroscience. American Psychologist, 54, 182-203.

Seidman, L. J., Giuliano, A. J., Meyer, E. C., Addington, J., Cadenhead, K. S., Cannon, T. D., McGlashan, T.H., ... North American Prodrome Longitudinal Study, G. (2010). Neuropsychology of the prodrome to psychosis in the NAPLS consortium: Relationship to family history and conversion to psychosis. Archives of General Psychiatry, 67, 578-588. doi:10.1001/archgenpsychiatry.2010.66

Seidman, L. J., Shapiro, D. I., Stone, W. S., Woodberry, K. A., Ronzio, A., Cornblatt, B. A., ... Woods, S. W. (2016). Association of neurocognition with transition to psychosis: Baseline functioning in the second phase of the North American Prodrome Longitudinal Study. JAMA Psychiatry, 73, 1239-1248. doi:10.1001/jamapsychiatry.2016.2479

Sergi, M. J., Fiske, A. P., Horan, W. P., Kern, R. S., Kee, K. S., Subotnik, K. L., ... Green, M. F. (2009). Development of a measure of relationship perception in schizophrenia. Psychiatry Research, 166, 54-62. doi:10.1016/ j.psychres.2008.03.010

Snitz, B. E., Macdonald, A. W., \& Carter, C. S. (2006). Cognitive deficits in unaffected first-degree relatives of schizophrenia patients: A meta-analytic review of putative endophenotypes. Schizophrenia Bulletin, 32, 179-194. doi:10.1093/schbul/sbi048

Sparks, A., McDonald, S., Lino, B., O’Donnell, M., \& Green, M. J. (2010). Social cognition, empathy and functional outcome in schizophrenia. Schizophrenia Research, 122, 172-178. doi:10.1016/j.schres.2010.06.011

Spreen, O. and Strauss, E. (1998) A compendium of neuropsychological tests: Administration, norms, and commentary (2nd Edition). New York: Oxford University Press.

StataCorp. (2017). Stata Statistical Software: Release 15. In. College Station, Texas: StataCorp LLC.

Stern, R. A., \& White, T. (2003). Neuropsychological Assessment Battery. Lutz, FL: Psychological Assessment Resources.

Stowkowy, J., Liu, L., Cadenhead, K. S., Cannon, T. D., Cornblatt, B. A., McGlashan, T. H., ... Addington, J. (2016). Early traumatic experiences, perceived discrimination and conversion to psychosis in those at clinical high risk for psychosis. Social Psychiatry and Psychiatric Epidemiology, 51, 497-503. doi:10.1007/s00127-016-1182-y

Thompson, A. D., Bartholomeusz, C., \& Yung, A. R. (2011). Social cognition deficits and the "ultra high risk" for psychosis population: A review of literature. Early Intervention in Psychiatry, 5, 192-202. doi:10.1111/ j.1751-7893.2011.00275.x

Thompson, A.D., Nelson, B., Yuen, H.P., Lin, A., Amminger, G.P., McGorry, P.D., ... Yung, A.R. (2014). Sexual trauma increases the risk of developing psychosis in an ultra high-risk "prodromal" population. Schizophrenia Bulletin, 40, 697-706.

Tienari, P., Wynne, L. C., Moring, J., Lahti, I., Naarala, M., Sorri, A., ... Laksy, K. (1994). The Finnish adoptive family study of schizophrenia. Implications for family research. British Journal of Psychiatry Supplement, 23, 20-26.

Tikka, M., Luutonen, S., Ilonen, T., Tuominen, L., Kotimaki, M., Hankala, J., \& Salokangas, R. K. (2013). Childhood trauma and premorbid adjustment among individuals at clinical high risk for psychosis and normal control subjects. Early Intervention in Psychiatry, 7, 51-57. doi:10.1111/ j.1751-7893.2012.00391.x 
Trauelsen, A.M., Gumley, A., Jansen, J.E., Pedersen, M.B., Nielsen, H.G.L., Haahr, U.H., \& Simonsen, E. (2019) Does childhood trauma predict poorer metacognitive abilities in people withfirst-episode psychosis? Psychiatry Research, 273, 163-170.

Trotta, A., Murray, R. M., \& Fisher, H. L. (2015). The impact of childhood adversity on the persistence of psychotic symptoms: A systematic review and meta-analysis. Psychological Medicine, 45, 2481-2498. doi:10.1017/ S0033291715000574

Turner, H.A., Finkelhor, D., \& Ormrod, R. (2010). Poly-victimization in a national sample of children and youth. American Journal of Preventive Medicine, 38, 323-330.

Ucok, A., Kaya, H., Ugurpala, C., Cikrikcili, U., Ergul, C., Yokusoglu, C., ... Direk, N. (2015). History of childhood physical trauma is related to cognitive decline in individuals with ultra-high risk for psychosis. Schizophrenia Research, 169, 199-203. doi:10.1016/j.schres.2015.08.038

van Dam, D. S., van der Ven, E., Velthorst, E., Selten, J. P., Morgan, C., \& de Haan, L. (2012). Childhood bullying and the association with psychosis in non-clinical and clinical samples: A review and meta-analysis. Psychological Medicine, 42, 2463-2474. doi:10.1017/S0033291712000360

van Os, J., Marsman, A., van Dam, D., Simons, C.J.; \& GROUP Investigators (2017). Evidence that the impact of childhood trauma on IQ is substantial in controls, moderate in siblings, and absent in patients with psychotic disorder. Schizophrenia Bulletin, 43, 316-324.

Varese, F., Smeets, F., Drukker, M., Lieverse, R., Lataster, T., Viechtbauer, W., ... Bentall, R. P. (2012). Childhood adversities increase the risk of psychosis: A meta-analysis of patient-control, prospective- and cross-sectional cohort studies. Schizophrenia Bulletin, 38, 661-671. doi:10.1093/schbul/sbs050
Vargas, T., Lam, P.H., Azis, M., Osborne, K.J., Lieberman, A., \& Mittal, V.A. (2019). Childhood trauma and neurocognition in adults with psychotic disorders: A systematic review and meta-analysis. Schizophrenia Bulletin, 45, 1195-1208. doi:10.1093/schbul/sby150

Velikonja, T., Fisher, H. L., Mason, O., \& Johnson, S. (2015). Childhood trauma and schizotypy: A systematic literature review. Psychological Medicine, 45, 947-963. doi:10.1017/S0033291714002086

Velikonja, T., Velthorst, E, McClure, M. M., Rutter, S., Calabrese, W., Rosell, D. Koenigsberg, H. W., Goodman, M., ... Perez-Rodriguez, M. M. (2019). Severe childhood trauma and clinical and neurocognitive features in schizotypal personality disorder. Acta Psychiatrica Scandinavica, 140, 50-64.

Velthorst, E., Nelson, B., O'Connor, K., Mossaheb, N., de Haan, L., Bruxner, A., ... Thompson, A. (2013). History of trauma and the association with baseline symptoms in an ultra-high risk for psychosis cohort. Psychiatry Researchearch, 210, 75-81. doi:10.1016/j.psychres.2013.06.007

Walker, E. F., \& Diforio, D. (1997). Schizophrenia: A neural diathesis-stress model. Psychological Review, 104, 667-685.

Wechsler, D. (1997). Wechsler Adult Intelligence Scale. San Antonio, TX: Psychological Corporation.

Weinberger, D. R. (1987). Implications of normal brain development for the pathogenesis of schizophrenia. Archives of General Psychiatry, 44(7), 660 669.

Widom, C. S., Czaja, S. J., \& Dutton, M. A. (2008). Childhood victimization and lifetime revictimization. Child Abuse \& Neglect, 32, 785-796. doi:10.1016/j.chiabu.2007.12.006

Zubin, J., \& Spring, B. (1977). Vulnerability: A new view of schizophrenia. Journal of Abnormal Psychology, 86, 103-126. 